\title{
علاقة الانفعالات بالاستعر افات واهميتها بالنسبة للعلاج المتمركز حول الشخص
}

Relationship of emotions with cognitions. Consequences for person-centered psychotherapy

ترجمة وإعداد: أ.د. سامر رضوان

أ.د. سامر جميل روأد رضوان

Prof. Dr. Samer Rudwan

University of Nizwa-Oman

ر.تاوش1

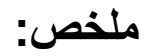

ظهرت في السنوات الاخيرة تفسيرات كثيرة للعلاقة بين المشاعر (العو اطف الاحاسيس) وبين الاستعر افات. سوف نتعرض في هذا المقال لنظرية لاز اروس هذه النظرية التي ايدتها وفصلتها نظرية كارل روجرز التي ترجع للعام (1951).

وقد أمكن هنا القيام بتفسيرات للتصرفات التي ما تزال متتوعة جداً بين المعالجين النفسيين وذللك على اساس القاعدة النظرية للارتباط بين الانفعالات والاستعر افات.

وقد خلصت دراسة استرشاديه Pilot Study إلى ان المعالج المعرفي لا يهتم إلا بالاستعر افات، في حين ان المعالج النفسي المتركز حول الثخص الذي يستخدم طريقة الموقف المركزي (البؤرة Focusing) يغلب اهتمامه بانفعالات المتعالج.

\footnotetext{
${ }^{1}$ Tausch, R. (1987). Der Zusammenhang von Emotionen mit Kognitionen. Konsequenzen für die personenzentrierte Psychotherapie. GwG Zeitschrift, 28-34.

1 راينهارد تاوش (من مو اليد 6 نوفمبر 1القانونية، نشفايغ، 8 أغسطس 34- 2013 في فورتسبورغ) كان في النصف الثاني من القرن العشرين أحد أهم علماء

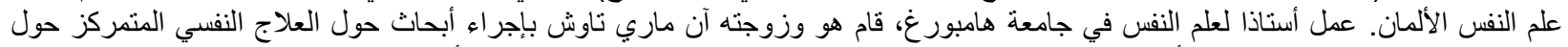

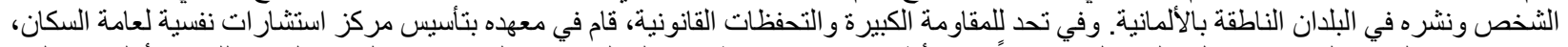

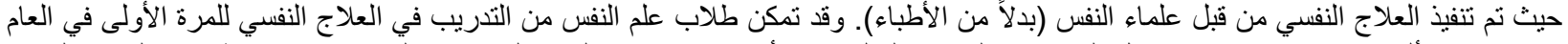

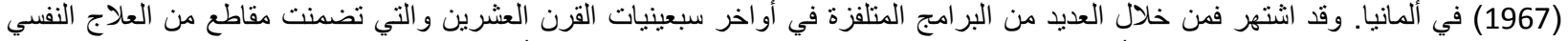

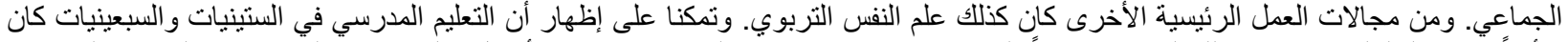

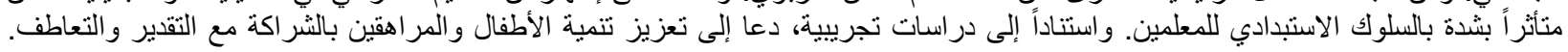

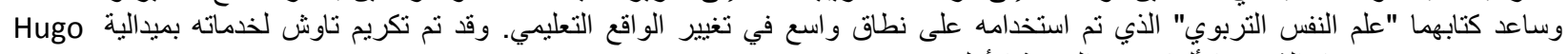

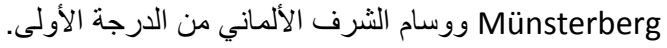


وفي الحديث المصور الذي اجراء كارل روجرز مع "غلوريا" اهتم في ثلثي (3/2) الحديث بمعرفيات المتعالجة وفي حوالي الربع (4/1) تقريباً بالانفعالات. ويبدو ان مثل هذا الاجر اء مقبول نو عاُ ما، في حين ان الاهتمام الغالب بمشاعر المتعالج يرتبط بعو اقب سلبية بالنسبة له.

ويبدو أن هناك سوء فهم عندما يستخدم التعبير الذي استخدمه روجرز “المشاعر” بمعنى Feelings “|نفعال” Emotion من الدداخل في العلاج النفسي والقهر. أقرب إلى الفهم من الناحية العلمية.

يحضر الكثير من المراجعين للعلاج النفسي بسبب المشاعر المتضررة وبسبب مشاعر القلق والانقباض ومشاعر النقص و الحيرة والذنب والقهر. فما هي الحوادث النفسية الاخرى التي ترتبط بها هذه المشاعر؟ وفهم ذلك يعتبر نظرياً ذا أهمية من اجل بناء اساس علمي للعمل النفسي العلاجي. يغلب ان يهتم المعالجون النفسيون المتمركزون حول الثخص بمشاعر المر اجعين بصورة مكثفة وعلى ما يبدو اكثر من المعالجين النفسيين بالعلاج السلوكي والعلاج المعرفي و التحليل النفسي.

اما في العلاج في المجموعة المتمركز حول الثخص فيحتل التعبير عن المشاعر مركزاً مثقدماً. فهل هذا الاهتمام بششاعر المتعالج او مشاعر المشاركين في المجموعة مفيد؟ ولماذا؟ ما الذي يحث في هذا؟ هل يمكن

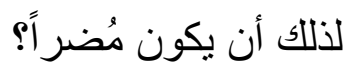

أرغب في العرض اللاحق عرض الآراء النظرية لريتشارد لازاروس R. S. Lazarus من جامعة بيركلي Berkeley

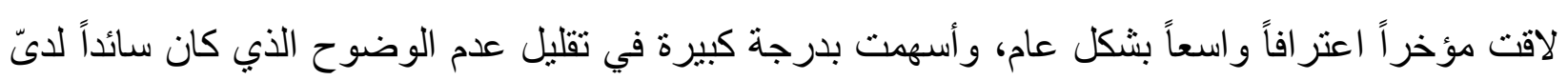
حتى الآن في هذا المجال و اعتبر ها اليوم بوصلة علمية ذات قيمة كبيرة في ممارستي العلاجية النفسية بالإضافة

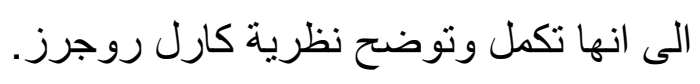

كتبت هذا المقال لاهتمام علمي من جهة، ولرغبتي في ان يصل المعالجون النفسيون بطريقة المعالجة المتمركزة حول الثخص ذوي التوجه التطبيقي الى علاقة أوثق بالنتائج النظرية لعلم النفس، بالإضافة الى ذلك اكتب هذا المقال لخشيتي ان اغلب المعالجين النفسيين لا يهيئون لمتعالجيهم شروطا مُعينة بسبب امكانية وجود نقص في المعارف النظرية. 


\section{1- الآراء النظرية لـ "ريتثارد لازاروس" حول المشاعر والاستعرافات:}

ارغب هنا بعرض الآراء النظرية بشكل مبسط ومختصر ، وذلك بالقدر الذي تكون فيه هذه الآراء ذات اهمية بالنسبة للمعالجين النفسيين المتمركزين حول الثخص. وسوف استند في هذا إلى ثلاثة من منشور اته (لازاروس1982؛ لازاروس وفولكمان 1984؛ لازاروس وآخرين 1980) وبإمكان القارئ المهنم الاطلاع على هذه المنشور ات.

1-الانفعالات_كالغصب والمخاوف و الغيرة: تعتبر مقدمة ونتيجة في الوقت نفسه للعمليات الاستعر افية

\section{.Cognitive Process}

العمليات الاستعر افية هي شرط ضروري وكاف ايضاً للانفعالات، وبهذا فالانفعالات ترتبط بشكل وثيق بالاستعر افات و الاستعر افات ضرورية جداً لما نشعر به.

\section{2- 2 - ماهي الاستعر افات (المعرفيات)؟}

قد يقود التعبير إلى سوء الفهم لحديثنا؛ فلا يُقصد بالاستعر افات التفكير المجرد او التفكير التأملي او الاستذهان2ntellectualization و لا ايضاً العمليات الاستعر افية التي تطلق على هذا النوع من العمليات في الدرس الصفي. "النشاط المعرفي لا يتضمن عند التقييم التفكير التأملي أو الوعي" (لازروس 1982، ص1022). إذ أنه حتى عند الحيوان هناك ايضا عمليات استعر افية ذات تأثير واضح على الانفعالات. فوعي النشاط المعرفي غير ضروري. الاستعر افات أو المعرفيات هي ادر اكات لمعنى الأحداث أو إدر اكات تقيبم لهذه الاحداث أوكليهما معاً من زاوية الأهية التي تمتلكها هذه الأحداث بالنسبة للصحة الثخصية أو لأفكار أو لتصورات أو المعتقدات الثخص حول نفسه ومحيطه. انها كل العمليات الاستعر افية حول الثخص، اي الادر اكات و الأفكار...الخ، التي تمتد لتشمل الثخص بذاته و علاقته بالمحيط الذي يشكله كل فرد بصورة فردية

ولها اهمية بالنسبة لحياته اليومية.

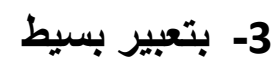

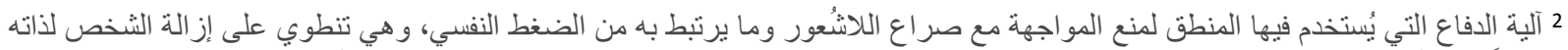

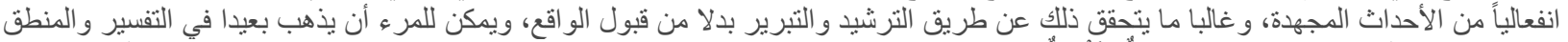

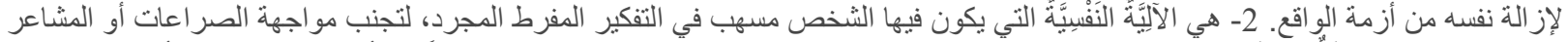

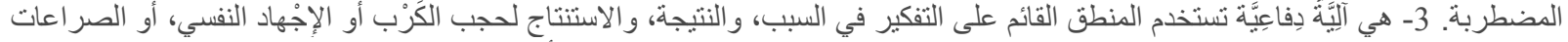

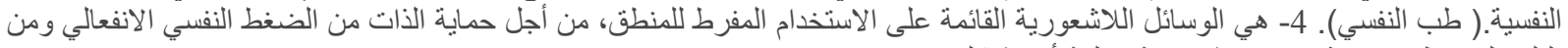

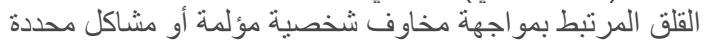


نحن نشعر حسب الاهمية التي ندركها وحسب الاحداث التي نقيّهها، و الافكار والآراء والتصورات التي نملكها حول انفسنا ومحيطنا. المشاعر هي نتيجة للأهمية التي ندركها ونتيجة لتقسيماتتا و افكارنا. فكل ارتكاس تتم اثارته من خلال ادر الك وتقييم معرفي مركب لأهمية الاحداث للصحة الذاتية. هذه الاحداث الاستعر افاتية تحدد الحوادث الانفعالية للإنسان في حياته اليومية. إن نوعية المشاعر التي يعيشها القارئ عند قراءة هذا المقال تتعلق بعملياته الاستعر افية القائمة على شخصه، اي تتعلق بتقييمه للمقال أو بالأهمية التي يدركها لهذا المقال. ان عملياته الاستعر افية تتأثر بمفاهيمه المنتكلة حتى الآن، وبخبر اته و الاهمية الددركة بالنسبة له. و على ما يبدو فان مجرد الادر الك وتقييم التعبير "عمليات استعر افية" قد ادى الى شعور مزعج عند عدد من الناس. 4- يتأثر إدر الك الاهمية والتقييمات بالخبرات السابقة وبالمفاهيم، كالدفاهيم الدينية و النظريات الثخصية

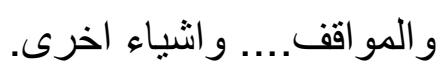
فاذا خبرنا حيو انا ما على أنه يشكل مصدر تهديد لنا وحصلنا على معلومات مطابقة من الآخرين حول ذللك فأننا سوف ننظر للحيوان في المستقبل على انه خطر علينا، نحن نقيّم هذا الحيوان على انه خطر

$$
\text { علينا ومعيق لسعادتنا. }
$$

5- تتعلق شدة المشاعر بمقدار الاهية التي نراها في حدث ما بالنظر لإحساسنا بالعافية.

$$
\text { 6- يمكن تعريف التقييمات حسب لاز اروس كما يلي: }
$$

- ما يسمى بالتقييمات الاولية Primary Appraisal وهي عبارة عن التقيمات للأشياء التي تعد مهمة للإحساس بالصحة الذاتية اثناء التعامل مع المحيط. ـ التقييمات الثنانوية Secondary Appraisal وتشتمل على التقييم الذاتي للثخص في موقف ما، اي مصادر الدعم، ضبطه للموقف وامكانات مواجهة الموقف (Coping). 7- يغلب جداً ان تتبع ذلك تقييمات جديدة" Reappraisal لموقف المحيط وللشخص ذاته وذلك على اساس خبرات أو معلومات جديدة. ويتم هنا تحول وتمايز الأهمية والتقييمات المدركة. أما التقييمات غير المناسبة لمصادر الدعم الذاتية فيتم تغيير ها عن طريق الخبرات. و عليه فانه يمكن للقارئ ان يكون في بداية قراعته لهذا المقال حول العمليات الاستعر افية قد شعر بالانز عاج بداية، ولكنه توصل بالتدريج إلى تقييم آخر ومن ثم إلى مشاعر اخرى. 
8- ترتبط الانفعالات و الاستعر افات بعضها ببعض بصورة وثيقة. وبغض النظر عن بعض عن بعض

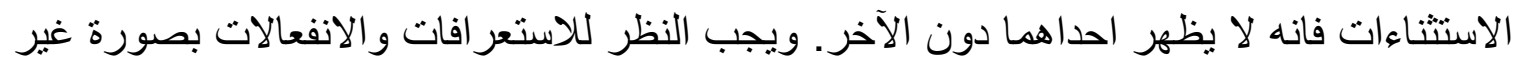
قابلة للفصل. ودائماً تقريباً تكون الششاعر غير خالية من الاستعر افات و العكس: فعندما تختفي اهمية

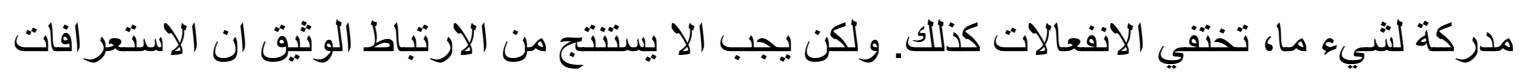

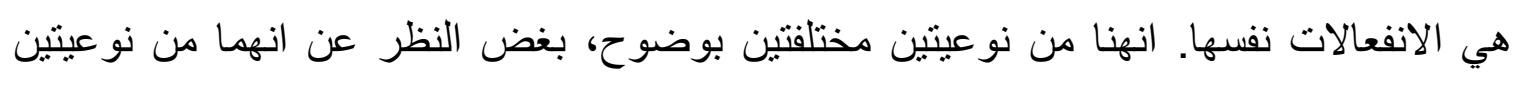
مختلفتين بوضوح، بغض النظر عن انهما يظهران.

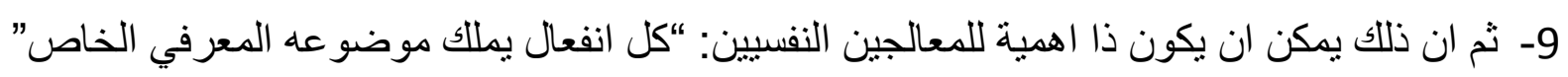
(لازاروس وآخرين 1980، صن200). بتعبير أخر: ترتبط كل نوعية وشدة انفعالية بنشاط معرفي محدد. وبالعكس هل يمكن للانفعالات ان توثر في العطليات الاستعر افية؟ (لاز اروس و آخرين 1980، ص 190) “ان الاهمية السبيية للعمليات الاستعر افية بالنسبة للانفعالات لا تعني ان الانفعالات لا تؤثر من جانبها بالاستعر افات". اذاً فليس ذللك عبارة عن طريق وحيد الاتجاه، الا انه ما يز ال قليل الوضوح. وباعتقادي ان هذا التأثير يتم على التحو التالي تقريباً: يدرك الثخص مشاعر معينة، وحسب تقييمها على انها ضارة او ملائمة او غير ضارة تتفوى مشاعره او تتخفض او تظهر مشاعر اخرى. فعندما يقيم الاشخاص الذهانيون حالات الاثارة لديهم او هلوساتهم

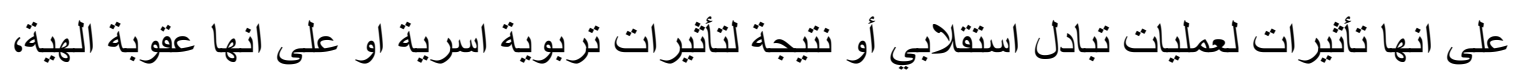

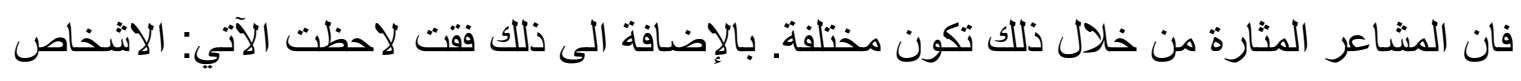
الذين يكونون في حالة استرخاء كبير يكونون اقرب لامتلاك افكار ومشاعر طيبة عن الماضي بالِي

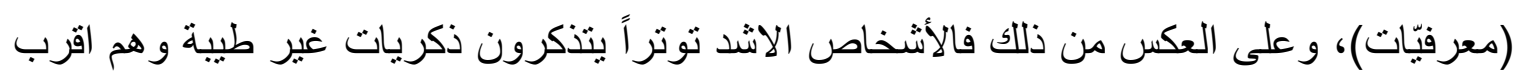

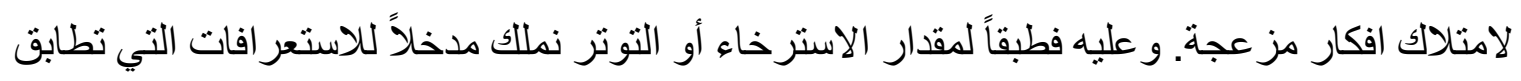
هذه المشاعر. على ما يبدو فإننا أيضاً نكون في وضعية عدم التكيف أكثر تصلباً في تقييماتنا، بينما في الحالة المسترخية نكون أقرب للمرونة و أقرب للتوصل لتنقيماعيمات متغيرة.

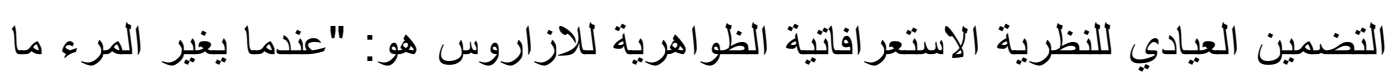

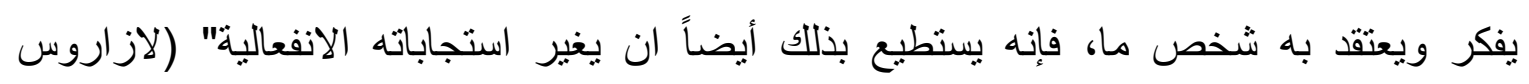

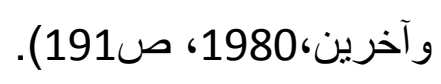


غالباً ما سمعت ان المعالجين النفسيين بطريقة المعالجة المتمركزة حول الثخص يققون تجاه

$$
\text { آراء لازاروس موقفاً أقرب للرفض. }
$$

إلا يتعرض المعالجون النفسيون بطريقة المعالجة المتمركزة حول الثخص بشكل جوهري

$$
\text { للمشاعر بدلاً من معرفيات المتعالج، خصوصاً في العلاج في المجمو عة؟3 }
$$

أجل: ان الآراء النظرية للازاروس تنبه جداً آراء كارل روجرز، رغم أنها قد أتت بعدها

$$
\text { بثلاثثن سنة، و أنها في بعض النقاط أدق. }
$$

يقول كارل روجرز في نظريته حول الشخصية والسلوك (1983، ص451-471).

1- يتصرف الشخص ويستجيب إلى حقل الادراك كما يخبره هذا الثخص وهذا يعنى

$$
\text { بمصطلحات لازاروس: ان الشخص يتصرف ويستجيب لمعرفيات. }
$$

2- تشكل الذات و إدر اك الشخص حول ذاته جزءاً مهما من حقل الادر الك، فعندما يقول المتعالج: "أني فانشل"، فإن هذا يعتبر تصريحاً حول استعر افاته، حول مفهومه عن ذاته كما بدرك هو. هذه الاستعر افية حول الذات تحدد سلوكه بوضوح، فعند روجرز يشكل مفهوم الذات معرفة عليا وهذه المعرفة يتم الالحاح عليها بشكل كبير.

وحسب نظرية لازاروس يعد الاستعر اف حول الذات مهمة بالنسبة للإحساس (وأيضا للسلوك) ولكن إلى جانب ذلك يتم التأكيد على الاستعر افات حول المحيط. 3- حسب روحرز فإن المشاعر ترافق السلوك وتنميه، ولأن السلوك ينتج عن الادراك، فإن المشاعر ترتبط بهذا الإدر الك. اعتقد ان لازاروس يرى ان هناك ارتباطاً وثيقة بين

$$
\text { الاستعر افات و الانفعالات. }
$$

4- ترتبط شدة المشاعر بالأهمية المدركة لحدث ما من أجل الحفاظ على العضوية وهذا ما

$$
\text { ير اه لاز اروس كذلك. }
$$

5- في حين يرى روجرز ان السلوك ينتج عن المفاهيم والأهمية المدركة وعن المشاعر المتعلقة بها، وان كان ذلك ليس هكذا مباشرة، فإن لاز اروس يملك مفهوماً موسعاً، فعنده

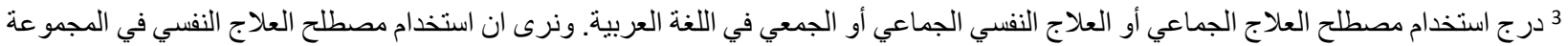

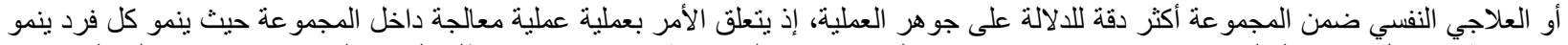

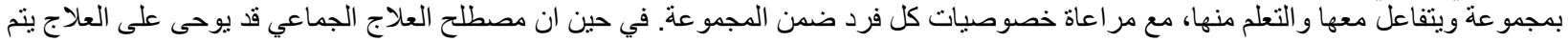
دفعة واحدة لكل مجموعة دون مر اعاة الخصائص الفردية. (مترجم). 
تكون كذلك التقييمات و التصور ات والآراء و الافكار حول المحيط وحول الثخص ذاته تابعة للاستعر افات.

\section{الانفعالات والاستعرافات في العلاج النفسي عند كارل روجرز: يتصف العلاج النفسي المتمركز حول الثخص بما يلي:} يهنم المعالج النفسي بالعالم الروحي الداخلي للمنعالج ويسعى لفهمه، ويبدي تفهمه للمتعالج دون تقييمات. ولكن بأي جزء من هذا العالم الداخلي يهتم المعالج النفسي: أيهتم بالإدر اكات، أم الذات أم المشاعر؟ يقول كارل روجرز (1983، ص23): "يتصف نشاط المعالج النفسي على الغالب بقدرته على إدر الك خبر ات ومشاعر المتعالج ومعناها الثخصي بدقة وحساسية. إنه احساس مباشر بالعالم الداخلي للمتعالج، بكل

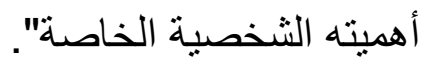

إذا فروجرز يهنم بالمشاعر ومعناها بالنسبة للشخص وتبدو وجهة نظر روجرز لعام (1959، ص198) في مثال نظري مهم أكثر وضوحاً. فهو يعرف الثعور (الاحساس Feeling): "انه تعبير يغلب استخدامه في كتابات ونظرية العلاج المتصركز حول الثخص، ويشير إلى خبرات متشربة انفعالياً (مشبعة

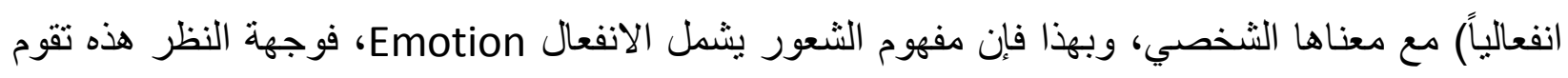
على وحدة الانفعال و الاستعر افات كما تعاش في اللحظة الر اهنة بشكل غير قابل للفصل".

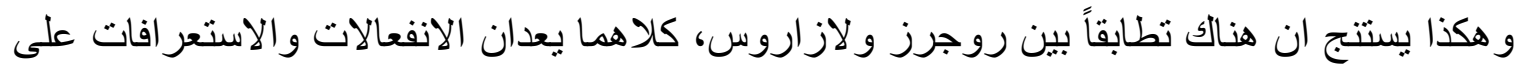

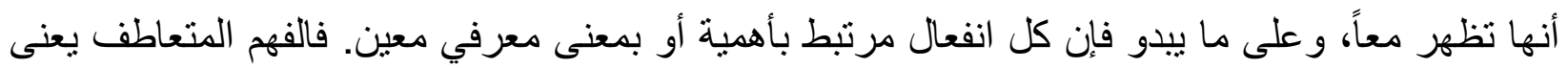

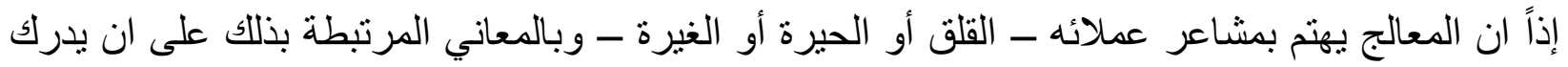
أو يقيم شخص ما شخصاً آخر على انه مهدد ومقيد أو مشؤوم.

و هذه الرؤية لروجرز قد لا تكون معروفة لدى بعض المعالجين النفسيين المتمركزين حول الثخص.

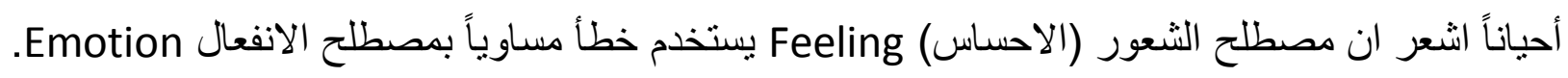
استنتاجات من التفسير النظري فيما يخص الاسلوب العلاجي النفسي: 
ما هي النتائج المستخلصة من نظرية الارتباط بين الانفعالات و الاستعر افات؟

كيف نستطيع مساعدة المتعالجين في ان يدركوا أو يقيمو أنفسهم ومحيطهم من خلال معنى آخر ،

بحيث يقود ذلك إلى تبدل في مشاعر هم المتأذية؟

أينبغي على المعالجين النفسيين الاهتمام باستعرافات متعالجيهم فحسب أم عليهم الاقتصار على

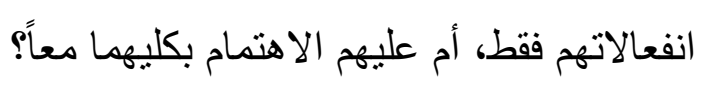

في دراسة استرشادية نوصلنا إلى ان هناك فروقاً غير عادية بين المعالجين النفسيين ذوي الاتجاهات

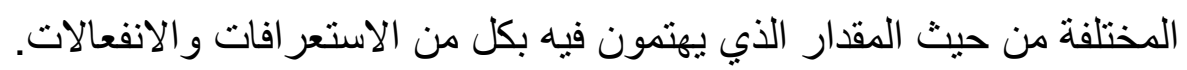

وقد أدى هذا الأسلوب الدختلف للمعالجين النفسيين إلى أن المتعالجين قد عبروا بمقادير مختلفة عن مشاعر هم واستعر افاتهم. لقد قمت في هذا البحث بتقييم مقاطع من جلسات لمعالجين نفسيين مختلفين ناطقين

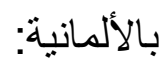

$$
\text { - الديفيد بورنس (1983)، ممثل العلاج المعرفي عند بيك (1981). }
$$

- لمعالج نفسي ألماني يؤلف بين علاج نفسي قائم على الثخص والطريقة التمركزية (البؤرة (Foucsing

وقد اخترت من كل معالج منهم مقطعين يحتويان على ليس أقل من خمس تعابير متعاقبة بين المعالج

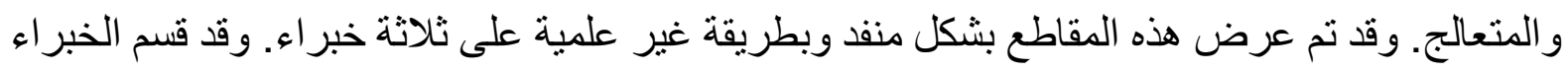
تصريحات المعالجين وتصريحات المتعالجين كل على حدة استتاداً إلى سلم مؤلف من خمس درجات لهات وذللك حسب كمية المحتوى من الاستعر افات و الانفعالات. وقد ظهر اختلاف شديد بين المعالجين النفسيين وكذللك عند متعالجيهم في مدى تطرقهم للاستعر افات و الانفعالات. وكان هذا الاختلاف دالاً احصائباً، ويتم حالياً التوسع بهذا البحث الأولى. 
و هذا يحصل عند المعالجين بطريقة العلاج المعرفي عند بيك (1981). يفترض بيك ان المشاعر،

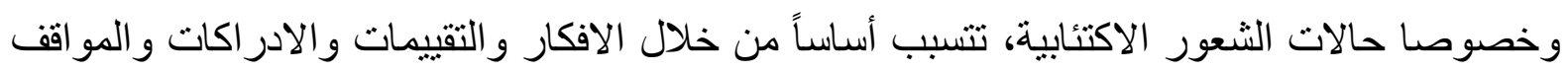
المتعلقة بالثخص وبالمحيط وبالمستقبل. "ويقول أول مبدأ من مبادئ العلاج المعرفي ان كل امزجنك تثار من خلال معرفياتك و أفكارك. ان المعرفة هي أسلوب كيفية در اكلك للأشياء، إضافية إلى و عيلك ومو اقفك وقناعاتكك وضمن ذلك أيضاً طريقة تفسيرك لمحيطلك والصورة التي تكونها حول شخص ما أو شيء ما. وان ما تشعر به في هذه اللحظة ينعلق بالأفكار لتي تكونها في هذه اللحظة". ما الذي يقودك إلى هذه

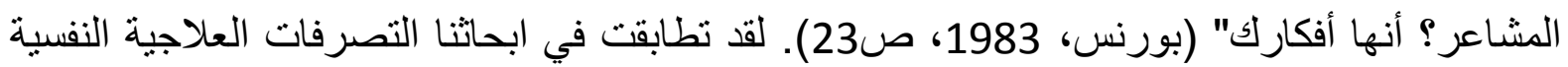
العملية عند بورنس مع هذه النظرية (وكذلك سلوك الجلسة (أسلوب المحادثة) لمعالج ألماني انفعاليعقلي وفق اتجاه اليز Ellis: لقد كانت النتائج مقدرة على سلم الخمس درجات كالتالي: تطرق المعالجين النفسيين للاستعر افات بمقدار 4.3 وللمشاعر بمقدار 1.5، بالإضافة إلى أن المعالجين قد تطرقوا إلى

$$
\text { معرفيات المتعالج بشكل أكبر من التطرق لمشاعره. }
$$

أما المتعالجين فقد تعرضوا في تعابير هم بمقدار 67\% لمعرفياتهم أكثر من مشاعرهم وفي 13\% إلى كليهما بالمقدار نفسه وفي 21\% فإن أسلوب المعالجين المعرفيين يملك الميزات التالية:

- لا يعزز المرضى المكتئبون بمشاعر هم السلبية وليس عليهم تركيز اهتمامهم عليها بشكل خاص. - - عندما يرى المتعالج ان مشاعره تحددها أفكاره وتقييماته، و عندما تنتشأ علاقة طيبة بالمعالج فربما سيبدأ المتعالج بعد بعض الوقت بالثنك بتقييماته وبتغير ها نو عاً ما. - - م أرى ان خطر العقلانية ضئيل لأنه ينم التحدث حول الاستعر افات المتمركزة على الثخص وحول الادر اكات و التقييمات التي يحملها بالنظر لذاته ومحيطه ومستقبله، غير انه يمكن وجود السلبيات

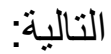
- يشعر المتعالج انه لم يفهم بعمق، ومن ثم يقنن خصوصاً في مشاعره، التي هي حقيقية بالنسبة له. ويمكن تخفيض هذا بأن يخبر المعالج المتعالج سبب عدم اهتمامه بمشاعره. - - - عندما يشعر المتعالج بالفهم هناك تلقينه - يظهر المعالج للمتعالج تشو هاته الاستعر افية ويقدم له معرفيات أخرى وهذا الأسلوب التوجيهي له مسو غاته عند المرضى الذين تكون لديهم تشويهات في الإدر اكات و الاخطاء في الاستعر افات 
واضحة جداً وخطيرة غير أنه لبس مبرراً في إرشاد المسترشدين. هنا يمكن للتقييمات الثخصية للمعالج و لأفكاره غير الملائمة ان تؤثر بصورة غير مناسبة عليه.

\section{غلبة اهتمام المعالجين بمشاعر المتعالج:}

يشجع بعض المعالجين النفسيين عملاءهم بشدة في الجلسات الفردية وعلى الاغلب في الجلسات ضمن المجموعة بالاهتمام المكثف بمشاعر هم. وانطباعي الثخصي يوحى ان المعالجين النفسيين المتمركزين حول الثخص قد زادوا في السنوات الخمس عشرة الاخيرة من الاهتمام بمشاعر متعالجيهم. ويعود ذللك إلى انه قد وجد في المجموعات المواجهة Encounter groups التي تتكون مما يسمى بالأسوياء، وجد ان اهتمام المشتركين بمشاعر هم وقد خبروه على انه محرر نفسياً، وعلى لهـ العكس من ذللك فقد قام المعالجون برفض اهتمام أعضاء المجموعات بالاستعر افات المتمركزة حول

$$
\text { الثخص على اعتبار أنه "عمل ذهني". }
$$

لقد قمنا بيحث الجلسة المنشورة لمعالج نفسي ألماني (روكيرت،1982) الذي يتبع توليفاً من العلاج النفسي المنمركزة حول الثخص مع طريقة التمركز (البؤرة Focusing) لغيندلين. وقد أظهر المعالج المتوسطات التالية على سلم الخمس درجات: التعرض للاستعر افات 1.7 وللمشاعرد

لقد تعرض المعالج في 65\% في تعبيراته لمشاعر المتعالج أكثر من تعرضه لمعرفياته وفي 16\% فقط تعرض للاستعر افات أكثر من المشاعر والثيء نفسه تقريباً كان في تعبيرات المتعالج. أما حسنات تعرض المعالج لمشاعر المريض: - يشعر المريض أنه مفهوم ويؤخذ على محمل الجد ومقبول في مشاعره، وهذا يؤدي إلى نوع من الاسترخاء وينمي علاقة طيبة مع المعالج النفسي.

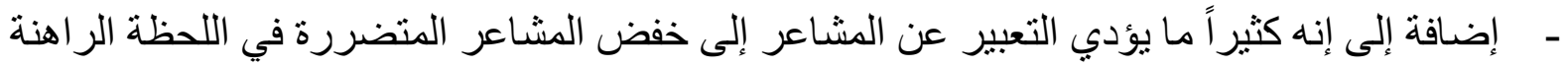

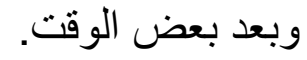
الا ان سلبيات هذا الاسلوب يمكن ان تكون: - ل اليقترب المعالج ومتعالجه من الثروط المثيرة للمشاعر ويتطرق المتعالج بصورة ضئيلة إلى

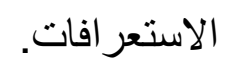


- يغلب ان ينطرق المتعالجين ذوو المشاعر المتضررة جداً إلى مشاعرهم السلبية وهذا يمكن ان يقود إلى تقوية هذه المشاعر. - غالباً ما يقود بعض لهوبه هده لمعالجين النفسيين عملاءهم إلى "إطلاق عدوانياتهم" إلى نوع من نراجع التوتر إلا أنه قلما يناقش المرضى الاستعر افات المحددة للمشاعر وبالتالي قلما يعون ذلك وأن يحصل تحول أو تعديل دائم. - من خلال الاهتمام الغالب بالمشاعر فإن المتعالجين - و على الاخص المتعالجات ـ يكونون أكثر صر احة و أكثر حساسية فيما يتعلق بشعور هن.

وفيما يتعلق بالحياة اليومية خارج نطاق العلاج النفسي، فإن النساء يملن إلى الصر احة الذاتية العاطفية أكثر من الرجال في حين ان الرجال يميلون للمعالجة العقلانية في الاحداث الثديدة (فوكس وتاوش، 1987). ولكن عندما يكون جزءً من مشاعر هم أقرب لأن يكون قلقاً ومتضرراً و عندما ينمي موقف المحيط هذه المشاعر فإن ذلك يمكن ان يؤدي إلى ان المتعالجين بعد العلاج النفسي يصبحون أكثر تضرراً من الناحية

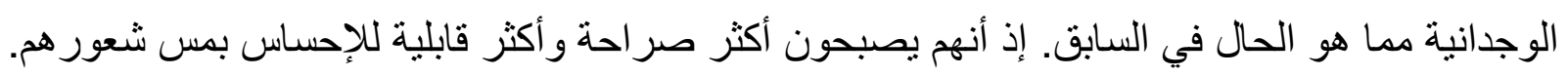
و على الرغم من أنهم يشعرون من خلال صر احتهم الكبيرة فيما يتعلق بخبر اتهم بتوسع ذواتهم (النمو الروحي)، فإن اضر ارهم الروحية قد تزداد ضمن الثروط المحيطية القاسية.

وقد عبر بورنس (1960، ص60) عن أفكار مشابهة "عندما نشعر بتحسن بعد المعالجة من خلال معالج متعاطف ومهتم فسوف يكون الارتياح لفترة قصيرة فقط، إذا لم تغير تقديرك لذاتك ونظام حياتك بشكل

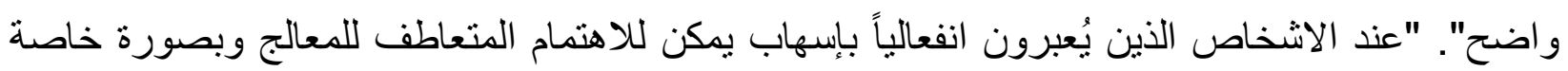

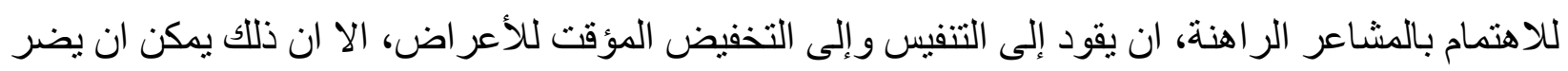

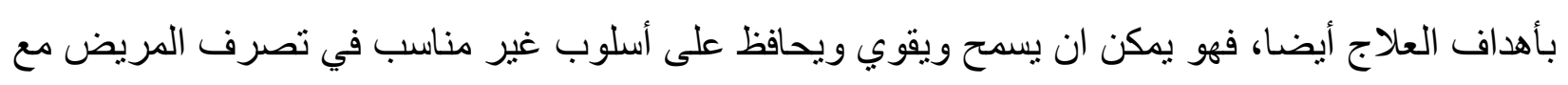
نفسه، ان مثل هؤلاء الأشخاص يحتاجون إلى تنمية عملياتهم العقلية أكثر من التعبير الحسي عن مشاعرهم وتتميتهم تكون أفضل عندما يقيمون ويحللون احساساتهم الوجدانية من ان يخبروها بشكل كامل (هاموند و آخرين، 1977، صنمن 
واخمن ان الاهتمام المكثق الغالب من قبل المعالجين النفسيين المتمركزين حول الثخص بمشاعرهم المتعالج أقرب إلى ان يؤدي إلى اطالة مدة العلاج وان تكون التغيرات طفيفة. ولا سيما وان المشاعر التي يعبر عنها المتعالجين في المحادثة الفورية أو ضمن المجموعة هي مشاعر مرهفة إنى على الغالب. تطرق المعالجين النفسيين لمعرفيات و انفعالات المريض: ان هذه الامكانية تتطابق على الاقرب مع رؤية كارل روجرز 1983:

التجاوب العاطفي للمعالج مع المتعالج يشمل مشاعره المعبر عنها وأهميتها الثخصية (استعر افية). وفي بحثنا لسلوك جلسة كارل روجرز في حديثه مع غلوريا (1956) استنتج ان هذا الرأي مطابق لسلوكه الفعلي: فقد بلغ المتوسط على سلم الخمس درجات عند كارل روجرز كالتالي: معالجة المفاهيم 3.3\%، معالجة المشاعر 2.3\%، وتطرق كارول روجرز في 67\% من تعبيراته للاستعر افات أكثر من الانفعالات وفي 13\% في المقار نفسه و21\% للانفعالات أكثر من الاستعر افات.

وقد ظهر هذا في سلوك المتعالج كذللك، فقد عبر المتعالجين في 56\% عن الاستعر افات أكثر من الانفعالات وفي25\% المقدار نفسه، وفي 19\% للانفعال أكثر من الاستعر افات.

تطرق المعالج لمعرفيات ومشاعر المتعالج بدرجة عالية (الدرجة من 3-5) كانت عند روجرز في

23\% من تعبير اته (عند المعالج المعرفي ديفيد بورنس 8\%، و عند المعالجين المتمركزين في 5\%).

هذا التطرق العلاجي لكارل روجرز في 3/2 من تعبير اته تقريبا إلى معرفيات المتعالج وفي 1/4 إلى

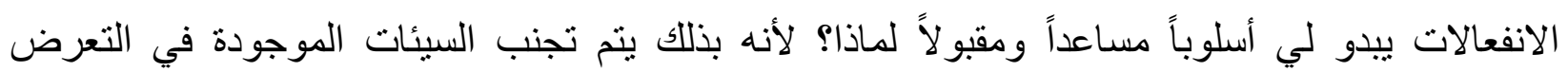
للانفعالات و الاستعر افات كل على حدة، ويتم استخدام مز ايا التوليف لكلا الإجر اعين بشكل أمثل: أما النتائج الملائمة للتطرق إلى معرفيات المتعالج فهي: - تؤثر الاستعر افات بصورة قطعية على احساسات المتعالج، فعندما يحدث هنا تعديل ما، فإن احساسه يتغير أيضاً. - - حتى عندما -قلما يتعلق الامر بشروط داخلية أو خارجية قابلة للتعديل (مرض سرطان مثلاً، موت قريب أو حالات اثارة في الادر اكات الذهانية) فإن كيفية تقييم المتعالج لهذه الثروط لثنابه

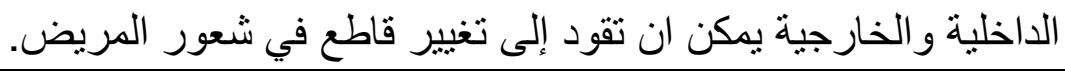


- وكما تظهر المعطيات، وطبقاً لنظرية لكارل روجرز يبدو ان التعرض شبه المستمر للمعالج إلى معرفيات المتعالج و انفعالاتهـ بمعنى علاجي - ذو أهمية لأنه بهذا بمكن ان تتم مخاطبة الانفعالات المرتبطة بمعرفيات معينة وبالعكس.

\section{حنات التعرض لمشاعر المتعالج المرتبطة بمعرفيات:}

- يشعر المتعالج بأنه مفهوم بعمق في خبرته العاطفية وهذا ينمي علاقة ملائمة بالمعالج، علاوة على ذللك: إذا شعر المنعالج ان المعالج يفهم مشاعره بدقة، فسوف يعقب ذلك نوع من تخفيف حدة التوتر. - يؤدي تخفيف حدة التوتر المر افق بالسبر لمعرفيات المتعالج إلى قلة الجمود في الاستعر افات ويزيد

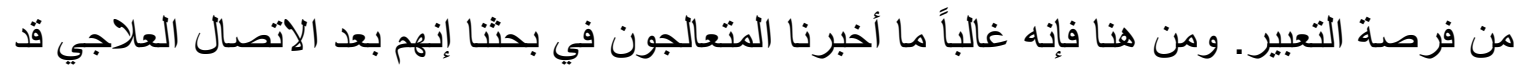
رأوا أنفسهم و الاحداث من منظور جديد.

- تقود المعرفة المعدلة نوعاً ما إلى نوع من التعديل في الثتعور، يدركه المتعالج من خلال تعرض المعالج للمشاعر المتبدلة، والثعور المتغير يمكن ان يقود إلى تبدل في الاستعر افات.

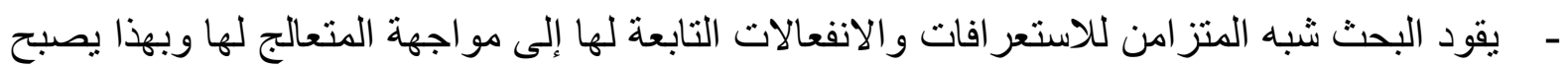
و اضحاً بالنسبة له عندما يعزو بصورة خاطئة مشاعر معينة إلى معرفيات محددة. - عندما يخاطب المعالج الاستعر افات والانفعالات المرتبطة بها فليس هناك أي خطر من ان يقوم المتعالج بعقلنة تجريدية أو يفصح عن مشاعره أو يغرقهما معاً. - من خلال التطرق المتوازي و المستمر للاستعر افات والانفعالات التابعة لها يحتاج المعالج إلى درجة دنيا من توجيه المتعالج؛ ويستطيع المتعالج استقصاء وفصص معرفياته في جزء جو هري منها وحده. - تخفيض المخاطبة المليئة بالتفهم واللاتقييمية لمشاعر المتعالج من خلال المعالج والتقبل التدريجي

للمشاعر من قبل المتعالج، يقلل من محاصرة وتصلب المدخل إلى الاستعر افات المرتبطة بها.

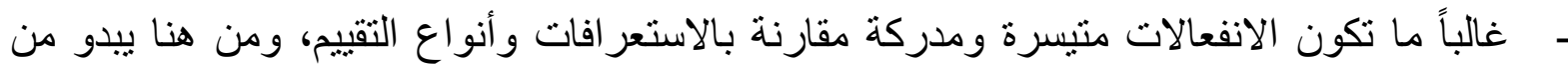
خلال ذلك وجود اتجاه مجسم، مدخل إلى معرفيات المرتبطة بها. - استناداً إلى الآراء النظرية الجديدة يبدو - بتعبير بسيط - ان الاستعر افات تكون مختزنة في الذاكرة مع الانفعالات أو مع الظلال الانفعالية المرتبطة بها، فالانفعالات يمكن ان تكون شيفرة مساعدة

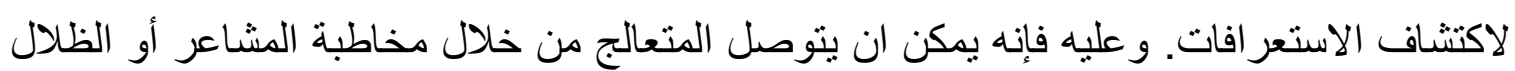
الانفعالية إلى المدخل إلى معرفياته المرتبطة بذللك. 


\section{شروحات اضافية للحدث العلاجي ـ النفسي من خلال نظرية الاستعرافية والانفعال:}

باعتقادي ان هناك امكانات كثثرة، لرؤية الحدث في العلاج النفسي بعد هذه التأملات. وفيما يأتي بعض

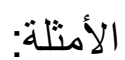

- ان ما يسمى بالسبر الذاتي يمكن ان نر اه على انه اكتشاف الاستعر افات المرتبطة بمشاعر معينة. إضافة إلى ان المعالجة الذاتية للتقيمات وتناقضات عزو الاستعر افات للانفعالات من حيث أن الأمر يتعلق بمعرفيات مرتبطة بالثخص، وباستناد المتعالج إلى مشاعره والإحساس بها، وذللك ليس عملية ذهنية مجردة للمشاعر و الأفكار. - عندما لا يقيم المعالج انفعالات ومعرفيات المتعالج باستمرار ويتقبلها كلها، فإن المتعالج سوف

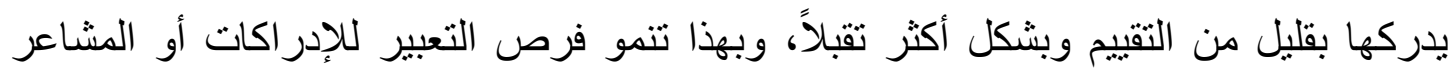
المشوهة المعزوة إليها معرفيات خاطئة، ومن هنا يمكن ان تظهر تقييمات جديدة. - يمكن لأصسالة معالج نفسي ما، التي تتمثل بر أينا في جعل المتعالج يفهم ادر اكاته وتقييماته الخاصة المختلفة الثدة، بصورة لا تقيمية ولا توجيهية، يمكن ان تكون مساعدة المتعالج عندما يكون

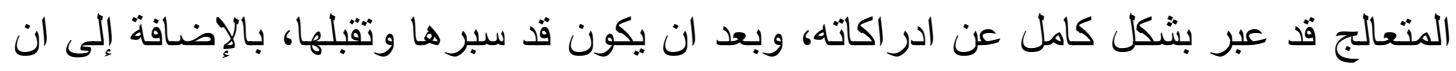
يبدو من الملائم ان يقوم المعالج بالمساعدة المتعالج على مواجهة وذلك عندما يظهر أو يعبر أعضاء المجمو عة للمتعالج عن تقييماتهم و ادر اكاتهم المختلفة. - يسنطيع المتعالج ضمن المجموعة معرفة كيفية تقييمه لنفسه والآخرين، فالثخص الذي يشعر بنفسه انه فانثل يمكن له من خلال خبرة و اقعية مكثفة، تكثف له انه رغم مشاعره غبر السعيدة فإنه محترم جداً من قبل أعضاء المجموعة، ان يعدل من تقييمه لذاته (معرفة ذاتية) وان يدرك وكئه نفسه كثخص محترم وان يشعر طبقاً لذلك.

- يمكن التعرض لمشاعر ومعرفيات المتعالج وتقبلها دون تقييم من خلال المعالج ان تؤثر جزئياً تجاه تقييمات الذات غير المناسبة، كتدخل وهمي، يسهل للمنعالج تحول معرفياته. - يمكن للمعلومات حول الاستعر افات المتعلقة بالثخص، منل الاستعر افات حول نمط حياة غير

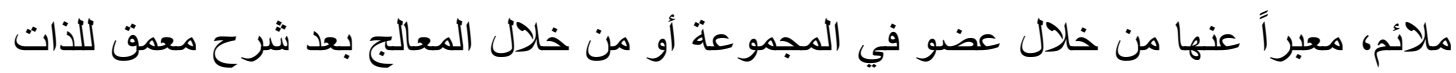
من قبل المتعالج ان يسهل تغيير معرفياته وبذللك شعوره. - يمكن لنا النظر للإجراءات النظرية من وجهة نظر فيما إذا وبأي مقدار تسهل حصول تحول في الاستعر افات. من خلال النشاط الرياضي وتمرينات الحركة على سبيل المثال والحوادث 
الفيزيولوجية المتغيرة، نظهر مشاعر جسدية أفضل، وتخفف من حدة التوتر، وتبدو مشاعر من النشاط، هذه الخبر ات تستطيع ان تغير من المعرفة الذاتية كما أظهرت الابحاث. - يمكن للتأملات و اليوغا ان تسهل للأشخاص الوصول إلى تغيير التقييمات حول ذاتهم وحول الآخرين من خلال حالة اللاتقييم وتخفيف حدة التوتر و الاحساسات الجسدية و الايجابية. - مع نقص التأكد التجريبي فأنه من غير الواضح عندي ما الذي يعينه مصطلح التمركز حول (البؤرة (Focusing) (غيندلين (1962) علمياً، من خلال وجهة نظر نظرية ـالاستعر افية

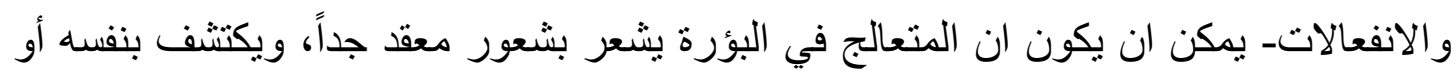
من خلال عرض المعالج الاستعر افات المرتبطة، إلا ان هذا حسب كارل روجرز هو حدث دائم

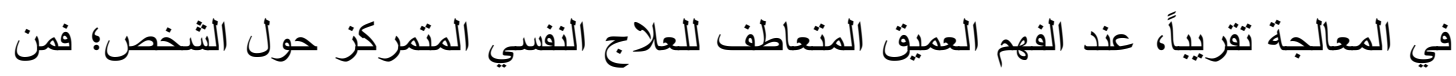
خلال التنسيق شبه التجريبي للبؤرة Focusing تظهر هذه العملية لوقت قصير. - - تحول الاستعر افات و التقييمات بالنظر للثخص ذاته أو المحيط ييدو المفتاح إلى تخفيض المشاعر المتضررة ولتنمية قدرة الوظيفة الروحية.

عندما نضع نحن المعالجين النفسيين، نصب أعيننا، ما هي الامكانات الاخرى غير المحادثات العلاجية النفسية، التي يمكن ان يحدث ذللك من خلالها فربما نستطيع مساعدة عملائنا بصورة أكثر. خاتمة:

اعتقد ان التوجهات العلاجية النفسية تستطيع على أساس من المعارف النظرية العامة المتوفرة الآن في علم النفس العلمي المساعدة على النظر للحدث العلاجي النفسي بصورة أكثر تفريقية. ومن خلال ذلك يستطيع العلاج النفسي المتمركز حول الثخص مع الكثير من أبحاثه التجريبية لكارل روجرز وآخرين الانضمام إلى علم النفس العلمي في الجامعات، وربما أمكن لعلم النفس العلمي أيضا التعلم من التوجهات العلاجية النفسية عندما ينظر إليها من وجهة إمكانات لتحويل الاستعر افات والتقييمات وبهذا امكانات لتحويل المشاعر. 